\title{
Revitalizing Traditional Chinese Concepts in the Modern Ecological Civilization Debate*
}

\author{
Finn Arler \\ Department of Planning, Aalborg University, Aalborg, Denmark \\ Email: arler@plan.aau.dk
}

How to cite this paper: Arler, F. (2018). Revitalizing Traditional Chinese Concepts in the Modern Ecological Civilization Debate. Open Journal of Philosophy, 8, 102-115.

https://doi.org/10.4236/ojpp.2018.82009

Received: February 8, 2018

Accepted: March 26, 2018

Published: March 29, 2018

Copyright (c) 2018 by author and Scientific Research Publishing Inc. This work is licensed under the Creative Commons Attribution International License (CC BY 4.0).

http://creativecommons.org/licenses/by/4.0/

(c) (i) Open Access

\begin{abstract}
The subject of this paper is the question of China's contribution to the establishment of an association of ecological civilizations-as seen from the perspective of a European-given the growing economic, political, and ecological influence that China has in the world today. The question is which values are likely to guide Chinese development. Can concepts like "sustainability", "environmental carefulness", and "common concerns of humankind" easily be integrated as topics on the Chinese agenda? Or are they likely to be expelled due to some basic values and ideas in traditional (or modern) Chinese worldviews? The paper discusses a number of modern interpretations that have argued that some basic concepts in the Chinese tradition are not only congenial with, but even provide fruitful additions to the modern debate about the establishment of cooperative ecological civilizations. In the final part the strong modern influence of both Marxist conceptions and consumerist behaviour is considered.
\end{abstract}

\section{Keywords}

China, Cultural Tradition, Environmental Values, Ecological Civilization, Sustainability, Ethics

\section{Background}

Like so many other Europeans before me, I find Chinese culture and society both fascinating and somewhat confusing; it is quite different from my own in a number of respects and yet strikingly familiar in many others. This is no less the case, when dealing with the issues that were brought up at the World Cultural Forum in Hangzhou 2013: exchanges and cooperation between the different

*This article is an improved and extended version of a paper presented at the World Cultural Forum in Hangzhou 2013. 
parts of the world in order to establish a sustainable association of ecological civilizations.

China has to play a very important part, if we shall succeed with this noble mission. Not only does one fifth of the world's population live in China. All the rest of us are also truly impressed-but also somewhat worried-about the fast economic growth that has taken place during the latest decades, and which is likely to continue for some time. For a number of years GDP growth rates have been higher than $10 \mathrm{pct}$. and are still around $7 \mathrm{pct}$. The industrial production growth rates have been even higher (CIA, 2018; World Bank, 2018). This is a change that matters on a global scale. China has always been a very important cultural and political player on the global scene, but the new economic performance has certainly taken both its economic and ecological impact to a new level.

The trouble is, of course, that significant industrial and economic growth not only results in higher living standards in the wealthiest parts of China. It is also followed by a number of serious environmental and resource-related consequences that can be expected to grow for many years (cf. e.g. Grumbine, 2007; Flavin \& Gardner, 2006). To mention just one example, in 2017 China emitted more than 10 billion metric tons carbon dioxide. This is more than 7.2 metric tons per capita, and three times as much as the emissions at the turn of the century (Global Carbon Project, 2017). In comparison, in my own country, Denmark, we emit 6.7 metric tons per capita, two third of what we did a couple of decades ago. The Intergovernmental Panel on Climate Change (IPCC) has recommended emission levels of no more than 1.3 metric tons on average per world citizens in order to avoid further climate changes, so both countries are faced with serious challenges here as well as in other environmental areas.

The Chinese Government is aware of this problem, and has launched two detailed national climate change programs (China's Government, 2007, 2012), where they present their interpretations of what the global Framework Convention on Climate Change's famous statement about "common but differentiated responsibilities" (FCCC, 1992) entails for China. The government has announced a proposal to build a national emission trading system in order to make the effort to reduce greenhouse gas emissions more efficiently (Shu, 2013). This is a clear sign that the government takes the problem seriously.

My task here is not to scrutinize government policy, though. Instead, my focus will be on values related to the establishment of an association of ecological civilizations-with a particular focus on the Chinese contribution, as seen from the perspective of a European. The obvious reason for doing this is the growing economic, political, and ecological influence that China has in the world today. What can we expect from China? Which kinds of values are likely to be guiding Chinese development? Can concepts like "sustainability", "environmental carefulness", and "common concerns of humankind" easily become topics on the Chinese agenda, or are they likely to be expelled due to some basic tenets in tra- 
ditional (or modern) Chinese worldviews? Can some of the basic concepts that are prevalent in the Chinese tradition even be seen as fruitful additions in modern debates about the establishment of cooperative ecological civilizations?

This is a daring task, of course. Firstly, in a country as huge as China with such a long and complex history, it would be strange to find just one unchallenged set of values. Cultures change substantially over time, in recent time even very quickly, and are far from homogeneous at any instant of time. Secondly, even though China, due to its size, has a more autonomous history than most other countries, the cultural interchange with the rest of world has been going on all the time. Influence from conflicting sets of Western ideas, particularly Liberalism, Marxism, Leninism and recently "Capitalist Consumerism" (Harris, 2004), has been significant during the latest century.

I have defined my task more narrowly, though, by confining myself to more limited groups of writers. These includes, first of all, a number of writers have tried to revitalize traditional Chinese concepts in the current ecological debate. It is doubtful whether it makes sense to talk about some authentic "Chineseness" that has been assailed from by foreign ideas, and which now ought to be revitalized as basis of a new époque, but at least such ideas have been put forward (cf. Miller, 2010; Tu, 2005). Secondly, Marxist ideology has dominated for so long that it may now be considered part of the Chinese legacy. This makes it worth considering separately. The Maoist version of Marxism even has a certain affinity with the Confucian tradition, as we shall see later. At the end of the paper I will discuss shortly whether a revitalization of traditional ideas is likely to make a difference in the present situation where consumerist patterns have become still more dominant.

\section{Following the Way of Nature}

During the latest couple of decades traditional Chinese (primarily Confucian, Daoist, and Buddhist) conceptions have been reintroduced by a number of authors with the explicit purpose of giving support to modern ecological, sustainability, zero- or degrowth positions with demands for limited intervention, small scale, organic methods, non-invasive technologies, animal-friendliness, etc. (cf. Tucker, 1991, 1993; Tu, 1989, 2001, 2005; Jenkins, 2002; Tianchen, 2003; Kemmerer, 2009), sometimes with the explicit intention to distance themselves from the influence of Western Enlightenment with its dualistic worldview, calculative rationality, reductionist science, and Faustian drive (e.g. Tu, 2001; Miller, 2012). These authors have tried to show that modern demands about sustainability are quite consistent with traditional views, particularly when contrasted with economic growth supporters' view of nature as nothing but a useful external source in need of control.

One should be cautious, when it comes to translating general ancient ideas into modern policy recommendation, and one ought to be somewhat alert about modern attempts to recover ancient, pre-scientific wisdoms with ideas that, after 
some interpretative effort, turn out to be surprisingly similar to those occurring in modern, global discourses (Rolston, 1987; Pedersen, 1995; Miller, 2010). Still, scepticism aside, there are a number of ideas in traditional Chinese thoughts that seem worthwhile to re-examine in the present debate about the prospects of an ecological civilization.

First of all, considerations about nature and the "natural way" have always been an integral part of traditional Chinese philosophy ( $\mathrm{Tu}, 2001$; Tianchen, 2003; Miller, 2010). A core principle of Daoism is that nature has its own harmonious and balanced way. Dao, or the "way of nature", is the basic principle of the universe, which organizes and structures everything in a way that leads to some kind of balance. This fundamental "way of nature" is also considered as the best criterion for human behaviour.

What human beings ought to do is wu-wei, literally "non-action", suggesting that one should drift along with the stream of life, and never invest in actions conflicting with the way nature flows. Humans should respect the rhythms of nature and avoid interrupting natural processes that, when left on their own, will lead to harmonious states. Confucianism predicates a human order whose rationality is based on the natural moral order of the universe, which, as we shall see shortly, promotes harmonic balance (Jenkins, 2002).

The Chinese synthesis of Confucianism and Daoism (with an important input from Buddhism) is typically presented as non-dualistic. This can only be partly true, though. If there is a "way of nature" that humans ought to follow, there have to be some "ways off nature" that lead them astray. Humans cannot be one with nature without reservations, if they can act contrary to it. Similarly, if humans ought to return to nature's way, they must have gone somewhere else in the meantime. If what humans have done is not an extension of nature (and so it would be, if humans were part of nature), what is it then? The route taken may be wrong for a number of reasons, but it must be one of nature's routes, if it can be taken at all.

This paradox can probably only be dissolved, if one accepts a dualism within nature itself. On the one hand there is ideal nature, nature at its best, i.e., when it flows its "natural way". On the other hand there is real nature as a whole, including both nature at its best and nature at its worst. In this case humans can be part of nature as a whole at the same time as they try to further nature at its best.

According to modern interpreters of traditional Chinese philosophies the basic goal of humanity is to ensure a positive correlation between humanity (ren), earth $(d i)$ and heaven or nature (tian) in order to generate an optimal state where all parties will flourish (Miller, 2012; Tu, 1989). This way the "way of nature" is also the "way of heaven" or "the way of the eternal moral order" (Tianchen, 2003; Miller, 2010). This does seem to support my suggestion of a double-sided concept of nature, where one part of the concept is primarily related to heaven-this is the perfectionist element, where we should search for the ideal "way of nature"-whereas the other part of the concept, nature as a whole, 
has a much stronger relation to earth and includes a variety of "ways off nature". This way, humans can be part of nature (as a whole) at the same time as they strive to find the more heavenly "way of nature".

\section{Circularity, Balance and Interconnectedness}

The idea of a triangular unity of earth, nature/heaven and humanity can be and has been interpreted in a number of ways (Lai, 2003), but in the recent debate it has primarily been seen as envisaging a place for humans within nature characterized by respectful interaction and reciprocity between humans and (the rest of) nature, and where humans find a more humble place in order not to block or ruin the grand circles of life (Tu, 2001; Shi, 2002; Kemmerer, 2009). This is based on a general assumption that the system as a whole, at its best, works as a balanced organism. Good is what further the flourishing of the system as a whole; evil is when the circulation of matter and cosmic energy ( $q i$ or $c h i$ ) is blocked with negative effects somewhere in the system (Munro, 1980).

These ideas obviously work smoothly with modern efforts to establish, e.g., a steady state economy (Daly, 1977) or a circular production system devoid of waste (McDonough \& Braungart, 2002; Ellen MacArthur Foundation, 2013). It is also fully compatible with ecological economists' insistence that the human economy is only part of a larger ecological system, and that economic expansion threatens balances crucial for ecological functions (Daly, 1977).

Human beings obtain materials and energy from a circular system, and they must return them to this system and do their best to reduce waste in order to avoid blockages and destruction. "Round and round goes the divine order of things", as the ancient Chinese put it. For Neo-Confucians frugality is a basic moral virtue; humans will end up suffering if they cannot control their aspirations. This, again, can be reinterpreted in a modern setting as a warning against over-consumption and one-sided commitments to economic growth leading to collapses in ecological systems (e.g., Jenkins, 2002).

The traditional circular image can, according to the Neo-Confucians, be contrasted with China's modernizers' view of "development" and "progress" as revolutionary concepts breaking with the continuous cyclical alignment of humanity, earth and heaven (or nature). The acknowledgment of perpetual circularity is replaced by an ambition of persistent alterations towards some positive future goal. This is the legacy from Western Enlightenment, no matter whether the inheritors are Marxists or Liberalist.

Several writers also emphasize that Neo-Confucian ecological ethics neither give humans any right to dominate the rest of nature, nor sacrifices human development in order to preserve pristine nature (e.g., Tianchen, 2003). NeoConfucians typically defend a unity of humankind and (the rest of) nature based on mutual respect or harmony between the two. On the one hand, humans are allowed to flourish without being ashamed of degrading nature simply by being here. On the other hand, love and friendship among humans ought to be ex- 
tended to the natural environment with the goal of establishing an "ecological harmony", where partial interests and overall interests, immediate interests and long-term interests are somehow aligned.

Even if interpretive caution is needed, there seems to be no doubt that traditional Chinese philosophy emphasizes a need for harmonious integration not only within the human world, but also in the relationship between humans and nature as a whole. Li even claims, on behalf of Neo-Confucianism, that "ecosystems are in urgent need of ethical consideration". In order to "save the environment" we must understand "our place within it, and our responsibilities toward it" (Tianchen, 2003).

Modern interpreters of Daoism similarly underline its demand of restraint and frugality and search for accordance with nature through the practice of $w u$-wei. This eventually leads up to some kind of Grand Unity, where everything becomes a seamlessly integrated part of the same harmonious organic whole. Apart from being co-partners of the same cosmic unity, humans are also similar to other organisms in many other respects. We can see ourselves in them and recognize them as other temporary manifestations of the same circular transformation process that we temporarily take part in, too. We should therefore treat them in a considerate manner, if not as brothers and sisters then at least as companions. Daoist precepts recommend coexistence with other living beings without hurting them, disturbing their homes, or eating their bodies (Tianchen, 2003; Miller, 2010; Kemmerer, 2009).

\section{Self-Cultivation and Impartiality}

A basic tenet that ties the ideal of harmony and balance to individual actions is the request for self-cultivation (dao in the Confucian tradition). Self-cultivation is a process that consists of an extension of considerations proceeding in concentric circles from oneself at the center to family, community, nation, and ultimately to all humanity. Each shift leads into a new stage in a continuous process, where the individual first transcends egoism, then parochialism, and finally chauvinist nationalism. A sense of connectedness and responsibility is extended to other communities, others regions and nations, and eventually to the globe or cosmos in total. The Confucian idea of self-cultivation has often been confined to human society, but Neo-Confucians' inclusion of Daoist traits makes it possible to see environmental problems as interruptions of a larger cosmic order (Tucker, 1991, 1993; Tu, 2001; Lai, 2003; Tianchen, 2003).

Core features of Confucian ethics that are important in the process of selfcultivation are benevolence (ren) (Tianchen, 2003), and "selflessness" or impartiality (Fang, 2012). There is a cognitive component involved in impartiality understood as selflessness-one must find the decision that is advantageous from the larger circles point of view-but the Neo-Confucian concept also contains an emotional dimension: empathy with and compassion for all things, especially but not only fellow humans. It is a basic task for each individual to develop one's 
predisposition to feel affection for others and to bond with them, to learn to empathize with fellow creatures and learn the right place for each thing (Munro 1980).

This idea has a modern parallel in the Norwegian philosopher Arne Næss' so-called Ecosophy T, according to which each living being have an equal right to live and unfold, and individuals undertake a self-realisation (or self-abnegation) processes, where their exclusive selfishness graduately disappear, until finally it is possible for them to say: "We seek what is best for ourselves, but through the extension of the self, our 'own' best is also that of all others" (Næss, 1989). People should learn the necessity to "touch the Earth lightly" through experiences with other living creatures, and develop an egalitarian attitude towards these through an "acknowledgment of the cycles of life and their interconnection in nature".

If people act selfishly, they separate themselves not only from their fellow citizens, but also from the interests of the larger community they are part of. Selfish people tend to be ignorant of the fact that they take part in a more comprehensive entity, and lack conscious affection for other parts of the "one body". This is intrinsically connected to another tenet, which is basic in Confucianism, but absent by Næss: knowledge of and obedience to social rules are an important part of the ideal life. Fulfillment of one's social role within a network of relations, of which the individual is an organic part, takes precedence over personal needs during the self-cultivation process. Individual quests for self-satisfaction in a narrow sense are therefore likely to be criticized for immature selfishness. The good of the organic whole should never be subordinated to interests of lesser units within it.

In order to avoid criticism individuals must submit to the rules issued within the largest relevant unit. The supreme authority must be expected to act on behalf of the largest public interest. This is a central thread that can be found running through both traditional and Maoist accounts: individuals and small groups are conceived in relation to some larger unit of which they are integral parts. Through the process of self-cultivation people realize that their most fundamental interests are those of the unit they are part of. One can compare this to an organ or a cell realizing that the health of the whole body is their most basic interest, not only because the body is a precondition for their own wellbeing, but in an even more fundamental sense: the body is what they live for, and they themselves may turn out to be dispensable.

There is an obvious danger of authorities making claims on true or basic interests of individuals, particularly if they themselves experience them as neither true nor basic. This problem is comparable to a well-known issue in the French philosopher Jean-Jacques Rousseau's idea of a social contract, where "each member is an indivisible part of the whole", and the citizen therefore "puts his person and all his power in common under the supreme direction of the general will" (Rousseau, 1762/1968). Citizens, who are unwilling to obey the general will, 
must be "forced to be free".

The metaphysics of cosmic unity never seems to have played a part in Maoism, but like Rousseau, it tended to consider individuals' basic interests as coextensive with duties towards the larger whole. People should accept the idea that the interests of the whole are their own most basic needs and regard them as attainable only through obedience to the prescripts from the centre. The Party established itself as the general will's representative, capable of identifying the interests of the whole, wherefore their recommendations became identical with the basic interest of all citizens. Individuals are thus helped in realizing their basic interest in a "higher kind of freedom". This permits rulers to force citizens, whose actions do not meet official approval, on the grounds that they do not understand their "true interests" (Munro, 1980).

In order to avoid these potentially totalitarian traits it is necessary to reinterpret the process of self-cultivation towards impartiality in other terms than selflessness. Brian Barry has suggested that we distinguish between two kinds of impartiality (Barry, 1995). First order impartiality implies that everybody is treated equally independent of his or her relation to an individual. If individuals give presents to their children, they must do likewise to all children, etc. This kind of impartiality easily ends in the kind of selflessness that lies open for totalitarian attacks.

With second order impartiality, on the other hand, individuals are allowed to have more comprehensive duties towards the individuals with whom they have the closest relations, first of all themselves, then their family, then their local community, and their nation, but these duties never become so pervasive that they prevent other people from acting in a similar way. The existence of other individuals or parties within each larger community set the limits on people's commitments towards themselves, their relatives, and their community, but without erasing the specific interests and commitments on each level. Love and friendship towards particular persons are allowed, even recommended, whereas fraud, nepotism, chauvinism, etc. are ruled out.

Peter Wenz has similarly suggested a Concentric Circle Theory (Wenz, 1988), according to which we all have the most comprehensive duties and commitments towards people in our innermost circle, i.e. ourselves, our families and close friends, and where the comprehensiveness diminishes as we move from the closest to larger circles ending with the largest circles that we can imagine, including, first, humankind, and secondly, all living creatures.

The fact that duties and commitments become still less comprehensive does not mean that they become less and less important. On the contrary, the duties towards all members of the largest circle are in some sense supreme, because they set the limits for duties in the next, smaller circle, etc. This way no one is left out, and no one needs to act out of total selflessness, because everybody are allowed to have special commitments to themselves and to members of their closest circles as long as this can be combined with similar rights for everybody 
else.

\section{The Marxist Legacy}

The fact that a Marxist-Leninist worldview has been capable of dominating Chinese thoughts for more than half a century, and that recently ideals of market based development has taken over very quickly, is a strong indicator that neither cultures nor philosophies are tightly sealed unchanging systems incapable of change. It indicates a cultural inhomogeneity that makes it possible for new influences to get a foothold. Foreign ideas are never doomed to fail, just because they are foreign.

Is Marxism compatible with eco-civilization, sustainability and degrowth? If we look at the ideas of growth and productivism dominating recent development in China, it is obvious that Marxist-Leninist ideology may have been quite influential in setting the course. One of its most basic thoughts is the idea of progress: the human species develops through a number of stages defined by the relations of production and with technological development as main driver.

Social justice and belief in continuously improved conditions for future generations are crucial elements, too, often at the expense of environmental considerations. Non-human nature has been of little interest in itself in the mainstream Marxist tradition, which in this sense belongs to the Western biblical tradition, where the wilderness outside the Garden of Eden must be conquered, subdued, and transformed into means of fulfilling still more refined human ends. Progress is an almost inevitable feature. Resource limits occur, of course, and sets progress on halt for a while, but sooner or later they will be overcome through technological innovation. Labour and technological ingenuity remain the main causes of value creation, not only in capitalist societies.

Karl Marx himself did now and again utter worries about his contemporary industry's devastating influence on its surroundings, particularly a loss of soil fertility that might threaten the "conditions of life required by the chain of successive generations" (Marx, 1894/1993). His partner Friedrich Engels underlined this even stronger, first of all in his description of the conditions of the working class in the large towns of England in 1844 (Engels, 1844/2009). But both quickly related environmental destruction to the uncontrolled influence of blind market forces in capitalist society and anticipated a more consciously planned development in future post-capitalist society.

According to the Marxist view of history, humans will finally release themselves from the blind powers-whether those of nature or those of capitalist market forces-that dominates the "realm of necessity", and jump into the ultimate "realm of freedom". Here they become true masters of nature, and will no longer be exposed to wasteful, ugly, and unhealthy conditions. A new set of collectivist relations of production is bound to release brand new forces of production that will make all previous barriers of necessity wither away.

It is far from obvious to what extent Marx himself expected this "realm of 
freedom", i.e., socialism or communism, to encompass continuous material growth, or rather, like John Stuart Mill, mainly thought of it in terms qualitative development (Mill, 1848/1965), but degrowth was certainly never an issue in traditional Marxism-Leninism. Nor was population control a concern in this tradition after Marx' harsh critique of Thomas Malthus. More people meant more freedom fighters in the struggle to humanize nature.

Mao Zedong was fully in line with this tradition of fighting for freedom against necessity, when he launched his famous "war against nature (tian)" (cf. Shapiro, 2000) - a war which was also conceived as the human will's war against fate, destiny and the preexisting order (other meanings of tian), as well as against all cosmic and social powers opposing the united will of the masses struggling for freedom and progress (Miller, 2010).

In some sense Mao even seems to have gone one step further and declared war against the very laws of nature-and against the advice of intellectuals and scientists who warned against the dangers of doing this. The united will power and energy of the masses were expected to work as substitute for scientific knowledge in the war on nature, a strategy with truly fatal consequences (Shapiro, 2000), even though one should be careful not to overlook differences over time and across the country (Ho, 2003).

It would be quite unfair to say that Marxism is incompatible with ideas of ecological civilizations, sustainability, and even degrowth. A significant number of modern scholars, who see themselves as participators in the greening of modern society, still work within a (revised) Marxist framework. They even tend to see the current development in China as a confirmation of the assumption that capitalist market relations constitute the essential part of the "realm of necessity", which is the main cause of environmental degradation, and which forecloses conscious planning in the "realm of freedom". This brings me to my final question, to what extent traditional and modern Chinese ideas are compatible with the request to develop an ecologically considerate civilization.

\section{Conclusion and Outlook}

We started by asking what we as Europeans can expect from China as a culture that in some respect is different from our own, and which kinds of values are likely to be guiding Chinese development. It is interesting, in particular, whether concepts like "sustainability", "environmental carefulness", and "common concerns of humankind" easily can become topics on the Chinese agenda, or rather are likely to be expelled due to some basic tenets in traditional (or modern) Chinese worldviews. We have further asked, whether some of the basic concepts that are prevalent in the Chinese tradition even may be seen as fruitful additions in modern debates about the establishment of cooperative ecological civilizations?

Even though one ought to be cautious about over-interpretations, the very fact that a number of interpreters see ancient ideas as kindred in many ways to mod- 
ern conceptions of sustainability, zero- and degrowth underpins these writers own thesis that nothing in the surviving elements of the traditional worldviews obstructs the introduction of these modern conceptions in a Chinese context. It is obvious, of course, that the modern interpreters may have searched for and highlighted exactly those bit and pieces, which support their own agenda, and that other traditional ideas pointing in other directions have been downplayed. Still, there does seem to be enough evidence to support the view that values and concepts, which resemble modern ideas of sustainability and ecological awareness, have had a prominent position in the written Chinese tradition.

It would be fair to add, too, that the long Chinese tradition of reflections on empathy with and compassion for both fellow humans and individuals from other species as well as the equally long tradition of seeing units as wholes within larger wholes add new tenets to other cultures conceptions of ecological civilization. This is the case, in particular, with the idea of the individual's task to seek self-realisation through developing one's predisposition to feel affection for others and to bond with them, to learn to empathize with fellow creatures and learn to find and develop a reasonable and harmoniously conceived place for oneself within a hierarchy of still more comprehensive wholes.

Since 1949, when a Marxist-Leninist-Maoist worldview became dominant in China, nature (tian) has mainly been regarded as external and subordinate to human conquest through the performance of will in combination with science and technology (Shapiro, 2000; Ho, 2001). In the Maoist fabric there has been a clear thread of the kind of Stalinism, which underlined the need to subjugate natural features together with all other obstacles to the victory of communism, and even accepted the sacrifice of whole generations on the altar of some quasireligious future ideals (Deutscher, 1966). On the other hand, it would be wrong to say that the Marxist legacy as a whole inevitable lead to neglect of environmental issues and human rights concerns.

As indicated by the large number of convinced and dedicated eco-socialists around the globe, the Marxist scepticism towards capitalist organisation forms and market based solutions need not be combined with an ideology of control and conquest of the natural environment. There are ideological components enough in the writings of Marx, Engels and their followers to support an ecofriendly civilizational course. So even though the Marxist legacy in modern Chinese ideology for a long time has been interpreted in a way that underlines and encourages humans' conquest and transformation of their natural surroundings, this legacy need not be an obstacle either.

What is actually more worrying is the fact that even at the heyday of Confucianism, Daoism, and Buddhism massive environmental degradation was already taking place, as documented, for instance, by the historian Mark Elvin (Elvin, 2004). This indicates that the determining factor does not need to be one or the other (elitist) philosophical system, but may be what Elvin has called "massive effects of the pursuit of power and profit" in a world full of possibilities 
(ibid.). Likewise, the origin of China's current environmental problems cannot be explained fully by the modernizers' rejection of traditional Chinese culture and the adoption of Western values. Mao's appeals about struggling with nature seem to have deep roots within Chinese culture and history itself (Miller, 2010).

It is not truly convincing to see all movements in history as epiphenomena of an essential blind and continuous fight for power and profit. Although this kind of struggle may be an ever-present part of life, it has certainly been organized in a number of different ways, including a number of civilized ones, and has lead to substantially different results. Nor is it convincing to think that the presence or absence of market forces in itself is sufficient to explain consumption patterns. Market forces are always regulated, promoted or blocked by political authorities, and this is always done in a specific way with a particular purpose. What is more: people are seldom just ignorant victims of such apparently uncontrollable forces, but are often quite satisfied with the impacts of their implementation.

Still, one may have doubts about how much the traditional ideas discussed in this paper are capable of influencing day-to-day policies, dominated not only by profit and power but also, in the current situation, by strong culturally founded consumerist trends, supported by political authorities (Harris, 2004). Many politicians and researchers all over the world seem to have forsaken any faith in fragile hopes for a paradigmatic philosophical change that is strong enough oppose consumerism and lead to a more harmonic cooperation with the rest of nature. Instead, they have put their ambitions in the so-called ecological modernization paradigm, which emerged in the wake of the Brundtland report with an optimistic ambition of creating a kind of economic growth that decouple the creation of wealth from environment damages and resource consumption, partly by way of smart state regulations, partly through voluntary contributions from committed companies and citizens.

However, even the downplayed prosaic ambition lurking behind the ecological modernization paradigm remains a hope for the development of a cleaner and less damaging interrelationship between humans and the rest of nature. In this sense there is continuity between this calm ambition and the more highflying ideals of ecological harmony and self-cultivation. Moreover, the ecological modernization ideal relies on the assumption that a decoupling of material and economic growth is a possibility. This may certainly work for some time, but nobody can say for how long. If significant economic growth continues for decades, it is hard to believe that decoupling and dematerialisation can continue to absorb the potential damages (Xue et al., 2011). Eventually it must come to an end, either because the impacts become overwhelming or because economic growth loses its attraction, and between now and then deliberations about which ideas to employ when dealing with this new situation may not be the worst way to spend one's time.

\section{Acknowledgements}

This article is based on a presentation at the World Cultural Forum in 
Hangzhou 2013. I would like to thank the organizers for their fruitful initiative and kind hospitality, as well as the audience for constructive comments.

\section{References}

Barry, B. (1995). Justice as Impartiality. Oxford: Clarendon Press.

China's Government (2007). China's National Climate Change Program. http://www.china.org.cn/english/environment/213624.htm

China's Government (2012). China's Policies and Actions for Addressing Climate Change. http://qhs.ndrc.gov.cn/zcfg/201111/W020120315680052698372.pdf

CIA (2018). The World Factbook. http://www.cia.gov/library/publications/the-world-factbook/geos/ch.html

Daly, H. (1977). Steady State Economics. The Economics of Biophysical and Moral Growth. San Francisco: W.F. Freeman.

Deutscher, I. (1966). Stalin: A Political Biography(2nd ed.). Harmondsworth: Penguin.

Ellen MacArthur Foundation (2013). Towards the Circular Economy. Cowes: Ellen MacArthur Foundation.

Elvin, M. (2004). The Retreat of the Elephants. New Haven \& London: Yale University Press.

Engels, F. (1844/2009). The Condition of the Working Class in England. D. McLellan (Ed.). Oxford: Oxford University Press.

Fang, X. (2012). Confucian Ethics and Impartiality: On the Confucian View about Brotherhood. Frontiers of Philosophy in China, 7, 1-19.

FCCC (1992). Framework Convention on Climate Change.

Flavin, C., \& Gardner, G. (2006). China, India and the New World Order. In: L. Starke (Ed.), State of the World 2006 (pp. 3-23). New York: Norton.

Global Carbon Project (2017). Global Carbon Atlas 2017. http://www.globalcarbonatlas.org

Grumbine, R. E. (2007). China's Emergence and the Prospects for Global Sustainability. BioScience, 57, 249-255. https://doi.org/10.1641/B570308

Harris, P. G. (2004). 'Getting Rich Is Glorious': Environmental Values in the People's Republic of China. Environmental Values, 13, 145-165. https://doi.org/10.3197/0963271041159831

Ho, P. (2001). Greening without Conflict? Environmentalism, NGOs and Civil Society in China. Development and Change, 32, 893-921. https://doi.org/10.1111/1467-7660.00231

Ho, P. (2003). Mao's War against Nature? The Environmental Impact of the Grain-First Campaign in China. The China Journal, 50, 37-59. https://doi.org/10.2307/3182245

Jenkins, T. N. (2002). Chinese Traditional Thought and Practice: Lessons for an Ecological Economics Worldview. Ecological Economics, 40, 39-52. https://doi.org/10.1016/S0921-8009(01)00263-4

Kemmerer, L. (2009). The Great Unity: Daoism, Nonhuman Animals, and Human Ethics. Journal for Critical Animal Studies, 7, 63-83.

Lai, K. L. (2003). Classical China. In D. Jamieson (Ed.), A Companion to Environmental Philosophy (pp. 21-36). Oxford: Blackwell.

Marx, K. (1894/1993). Capital: A Critique of Political Economy (Vol. 3). London: Penguin Classics. 
McDonough, W., \& Braungart, M. (2002). Cradle to Cradle. Remaking the Way We Make Things. New York: North Point Press.

Mill, J. S. (1848/1965). Principles of Political Economy. Toronto: University of Toronto Press.

Miller, J. (2010). Humans Must Conquer Nature: Philosophical and Religious Sources of China's Anti-Environmental Ideology. Journal of the Royal Asiatic Society, 74, 1-20. http://qspace.library.queensu.ca/handle/1974/7252

Miller, J. (2012). Daoism and Sustainable Development. http://catspaw.its.queensu.ca/handle/1974/7273

Munro, D. J. (1980). The Concept of "Interest" in Chinese Thought. Journal of the History of Ideas, 41, 179-197. https://doi.org/10.2307/2709455

Næss, A. (1989). Ecology, Community and Lifestyle. Translated and Revised by David Rothenberg, Cambridge: Cambridge University Press. https://doi.org/10.1017/CBO9780511525599

Pedersen, P. (1995). Nature, Religion and Cultural Identity: The Religious Environmentalist Paradigm. In O. Bruun, \& A. Kalland (Eds.), Asian Perceptions of Nature: A Critical Approach (pp. 258-276). London: Curzon Press.

Rolston, H. (1987). Can the East Help the West to Value Nature? Philosophy East and West, 37, 172-190. https://doi.org/10.2307/1398737

Rousseau, J.-J. (1762/1968). The Social Contract. Harmondsworth: Penguin.

Shapiro, J. (2000). Mao's War against Nature: Politics and the Environment in Revolutionary China. Cambridge: Cambridge University Press.

Shi, T. (2002). Ecological Economics in China: Origins, Dilemmas and Prospects. Ecological Economics, 41, 5-20.

Shu, W. (2013). China Gets Ready for a New Carbon Era.

Tianchen, L. (2003). Confucian Ethics and the Environment. Culture Mandala: The Bulletin of the Centre for East-West Cultural and Economic Studies, 6, Article 4.

$\mathrm{Tu}$, W. (1989). The Continuity of Being: Chinese Visions of Nature. In J. B. Callicott, \& R. T. Ames (Eds.), Nature in Asian Traditions of Thought: Essays in Environmental Philosophy (pp. 67-78). Albany, NY: University of New York Press.

Tu, W. (2001). The Ecological Turn in New Confucian Humanism: Implications for China and the World. Daedalus, 130, 243-264.

Tu, W. (2005). Cultural China: The Periphery as the Center. Daedalus, 134, 145-167.

Tucker, M. E. (1991). The Relevance of Chinese Neo-Confucianism for the Reverence of Nature. Environmental History Review, 15, 55-69. https://doi.org/10.2307/3984970

Tucker, M. E. (1993). Religious Values Derived from Other Traditions: Ecological Dimensions of Taoism and Confucianism. Dialogue and Alliance, 7, 86-97.

Wenz, P. S. (1988). Environmental Justice. New York: State University of New York Press.

World Bank (2018). World Bank Data.

Xue, J., Arler, F., \& Næss, P. (2011). Is the De-Growth Debate Relevant to China? Environment, Development and Sustainability, 14, 85-109. 